\title{
Reliability and validity of the Medication Adherence Rating Scale in a cohort of patients with schizophrenia from Nigeria
}

\author{
Confiabilidade e validade da Medication Adherence Rating Scale em uma coorte \\ de pacientes com esquizofrenia na Nigéria
}

Godspower O. Owie, Sunday O. Olotu, Bawo O. James

\begin{abstract}
Introduction: Assessing adherence in schizophrenia facilitates interventions that optimize outcomes. Adherence rating questionnaires are feasible and non-intrusive; however, no validated measure exists in sub-Saharan Africa. We aimed to assess the psychometric properties of the 10-item Medication Adherence Rating Scale (MARS).

Methods: This was a cross-sectional study of a cohort of patients with schizophrenia $(n=230)$. A sociodemographic questionnaire, the Mini International Neuropsychiatric Interview (MINI), Positive and Negative Syndrome Scale (PANSS), Scale for the Unawareness of Mental Disorder (SUMD) and the MARS were all administered by an interviewer.

Results: The MARS demonstrated good reliability (Cronbach's alpha: 0.76). The scale was reducible to a 3-factor construct (1 - medication adherence behavior, 2 - attitude to taking medications, and 3 - negative side effects and attitude to psychotropics), with significant though weak external validity in relation to psychopathology $(p<0.001)$ and insight $(p<0.001)$. The first factor showed good internal consistency $(a=0.80)$, comprising six items that could serve as a reliable proxy measure of adherence in place of the MARS

Conclusion: The MARS demonstrated fair psychometric characteristics in assessing adherence in patients with schizophrenia in this cohort. The scale may be useful in the dimensional assessment of medication adherence for schizophrenia in sub-Saharan African settings.
\end{abstract}

Keywords: Medication adherence, schizophrenia, rating scale, reliability, validity.

\section{Resumo}

Introdução: Avaliar adesão ao tratamento na esquizofrenia facilita intervenções que otimizam desfechos. Questionários de avaliação da adesão são factíveis e não intrusivos; no entanto, não há uma medida validada na África subsaariana. O objetivo deste estudo foi avaliar as propriedades psicométricas da escala de 10 itens intitulada Medication Adherence Rating Scale (MARS).

Métodos: Este foi um estudo transversal de uma coorte de pacientes com esquizofrenia $(n=230)$. Um questionário sociodemográfico e os instrumentos Mini International Neuropsychiatric Interview (MINI), Positive and Negative Syndrome Scale (PANSS), Scale for the Unawareness of Mental Disorder (SUMD) e a MARS foram todos administrados por um entrevistador.

Resultados: A MARS demonstrou boa confiabilidade (alfa de Cronbach: 0,76). Foi possível reduzir a escala a um construto de 3 fatores (1 - comportamento de adesão à medicação, 2 atitude em relação a tomar medicação, e 3 - efeitos colaterais negativos e atitude em relação aos psicotrópicos), com validade externa significativa, embora fraca, em relação à psicopatologia $(p<0,001)$ e ao insight $(p<0,001)$. O primeiro fator mostrou boa consistência interna $(a=0,80)$, incluindo seis itens que poderiam servir como uma medida substituta confiável de adesão no lugar da MARS

Conclusão: A MARS demonstrou características psicométricas satisfatórias ao avaliar adesão em pacientes com esquizofrenia nesta coorte. A escala pode ser útil na avaliação dimensional da adesão ao tratamento para esquizofrenia em contextos africanos subsaarianos.

Descritores: Adesão à medicação, esquizofrenia, escala, confiabilidade, validade. 


\section{Introduction}

There is evidence that persons with schizophrenia are poorly or non-adherent to medications. In subSaharan Africa, the magnitude of poor or non-adherence is huge. ${ }^{1-5}$ Direct comparison of the prevalence and determinants of poor or non-adherence with reports from Europe and North America is limited by differences in methodology and case ascertainment criteria. While some studies utilize non-standardized methods of indirectly ascertaining the magnitude of poor or nonadherence, others utilizing validated measures report conflicting findings. ${ }^{6}$

Poor or non-adherence to medication should not be restricted to a dichotomous division between poor or good adherence, but should rather examine the concept as a dimension that would guide appropriate intervention. ${ }^{7}$ Unlike other measures of adherence, the Medication Adherence Rating Scale (MARS) describes an individual's medication adherence in three dimensions: medication adherence behavior, attitude toward taking medication, and negative side effects and attitudes to psychotropic medication. ${ }^{7}$ Indeed, self-report measures of medication-taking behavior overestimate adherence when compared to objective measures, ${ }^{8}$ and this is perhaps why it has been argued that aside from medication-taking behavior, self-report measures should also assess for barriers to adherence and beliefs. ${ }^{9}$

The MARS has not been well utilized in sub-Saharan Africa: the authors only identified one previous report. ${ }^{10}$ The MARS is a 10 -item self-report questionnaire developed after combining the Medication Adherence Questionnaire and the Drug Attitude Inventory. ${ }^{11}$ The developers validated this tool in patients with psychosis and reported good psychometric properties (reliability and validity) in a moderately sized sample. Fialko et al. ${ }^{12}$ confirmed the three-dimensional factor structure of the MARS but reported low internal consistency. The three-dimensional structure was also confirmed in a population of homeless patients with schizophrenia across France. ${ }^{13}$

No study has assessed the validity of the MARS in a non-western setting. There is also a need to utilize a brief assessment tool for medication adherence research in schizophrenia in these settings, facilitating the development of specific interventions to improve schizophrenia treatment outcomes. This study therefore aimed to assess the psychometric properties of the MARS in a schizophrenia cohort receiving outpatient care at a regional psychiatric hospital in Nigeria.

\section{Methodology}

\section{Setting}

This study was undertaken at the outpatient department of the Federal Neuro-Psychiatric Hospital (FNPH), in Benin City, Nigeria. The hospital is a 230-bed facility that provides in- and outpatient care, as well as emergency services to persons with mental illnesses.

\section{Participants}

Outpatients aged between 18 and 64 years, able to communicate in English language, clinically diagnosed using the ICD-10 by a consultant psychiatrist, and who had received care for at least six months prior to study recruitment were invited to participate. Patients who were acutely ill, who presented with a co-morbid physical illness or who declined to participate were excluded.

\section{Ethics}

Ethical clearance was obtained from the ethics committee of the Federal Neuro-Psychiatric Hospital, in Benin City, Nigeria, prior to the commencement of the study. Permission was also obtained from the management of the hospital and the consultant psychiatrists in charge of the clinics to be used for the study. Questionnaires carried no names, in order to ensure participant anonymity and confidentiality. The study did not involve conducting any invasive tests, nor did it affect the quality of care. Acceptance to participate in this study was voluntary, and all responses were treated anonymously and confidentially. Participants were included in the study after they provided signed written consent.

\section{Instruments}

Sociodemographic questionnaire

This instrument was developed by the researchers to collect data on age, gender, ethnicity, educational status, marital status, and occupation (using criteria from the International Standard Classification of Occupations - 2008 [ISCO-08]). Information on religion, town of residence, number of years/months since the diagnosis was made, and number of admissions (if any) due to the diagnosed illness was also extracted.

\section{Medication Adherence Rating Scale (MARS)}

The MARS is a 10 -item self-reporting multidimensional instrument describing three dimensions: medication adherence behavior (items 1-4), attitude toward taking medication (items 5-8) and negative side effects and attitudes to psychotropic medication (items 
9-10). Medication adherence behavior refers to the intensity of drug use during the duration of therapy and persistence during the overall duration of therapy. Attitude to psychotropic medication measures beliefs about medications, while negative side effects assess side effects as a barrier to medication adherence. Scores for each dimension are obtained by summing the items within each dimension. Each question has a yes or no response. A response consistent with non-adherence is coded as 0 , whereas a response consistent with adherence is coded as 1 . For questions 1-6 and 9-10, a no response is indicative of adherence and is coded as 1 , while for questions 7 and 8, a yes response is indicative of adherence and is coded as 1 . Total scores on the MARS may range between 0 and 10 , with a higher score indicating better medication adherence. The MARS was developed by Thompson et al. ${ }^{7}$ as an improvement on the Drug Attitude Inventory and the Morisky Adherence Questionnaire, and has several advantages and qualities. For instance, unlike the Drug Attitude Inventory, the MARS provides more information on behaviors that may be associated with unintentional poor adherence to the use of medication, such as forgetfulness, and those associated with intentional poor adherence, such as side effects of medications. It is a widely used instrument, 7,12 which reflects an understanding of adherence as a continuous variable. The MARS assesses adherence as a multidimensional phenomenon, and the findings are analyzed as dimensional rather than as categorical variables. The MARS has shown good psychometric properties, with Cronbach's alpha of 0.77 and internal consistency reliability of $a=0.75$. It satisfactorily predicts non-adherence. ${ }^{7,12}$ It has also been used in Nigeria. ${ }^{10}$

\section{Mini International Neuropsychiatric Interview (MINI)}

English version 5

The MINI is a short structured diagnostic interview developed by Sheehan et al. ${ }^{14}$ It is used to diagnose major axis 1 psychiatric disorders based on DSMIV and ICD-10 criteria. It has good inter-rater and retest reliability. The MINI has been used in studies on schizophrenia in Nigeria. ${ }^{15-17}$ The psychosis module was used to confirm the diagnosis of the patients in the present study.

\section{The Positive and Negative Syndrome Scale (PANSS)}

The PANSS was administered to all participants to assess symptom severity. ${ }^{18}$ The PANSS has subscales (positive, negative, and general psychopathology) and a composite index. The positive and negative subscales have seven items each, with scores ranging from 7-49; the general psychopathology subscale has 16 items, with scores ranging from 16-112.
The scale has been found to be a valid and reliable means of measuring symptoms of schizophrenia. The instrument has been used extensively in studies on schizophrenia in Nigeria. ${ }^{19,20}$

Scale to Assess Unawareness of Mental Disorder (SUMD)

This is a semi-structured interview questionnaire designed to assess insight. The abbreviated version of the SUMD was used in this study. It has a total of 11 domains and 6 items that describe 3 dimensions: awareness of the mental disorder and response to medications (items 1 and 2), level of awareness of positive symptoms (items 3 and 4 ) and level of awareness of negative symptoms (items 5 and 6). Each of these domains is rated on a 5-point Likert scale, with higher scores indicating poorer insight for each domain. The scale assesses insight on each domain on the basis of awareness and attribution of symptoms. This instrument has also been used previously in Nigeria. ${ }^{19}$

\section{Pilot testing}

We pilot-tested the MARS to determine that the questions were easily understood. We decided that the MARS as well as other rating scales would be administered by the researchers to facilitate understanding of each question. We identified that low level of education among some participants would make it difficult for them to read the questions; however, understanding was usually improved if questions were read out loud. A similar method has been employed in Brazil. ${ }^{21}$

\section{Data analysis}

We entered data from paper questionnaires into an electronic spreadsheet (SPSS version 21). We summarized data using descriptive statistics and presented them in tables. Bivariate analyses were conducted using two tailed $t$-tests, and correlations were conducted using Pearson's correlations following normality testing using Kolmogorov-Smirnov tests. Confirmatory factor analysis was performed to delineate the factor structure of the MARS in this cohort. Level of significance was set at $p<0.05$ a priori.

\section{Results}

\section{Sociodemographic characteristics}

The mean age (standard deviation) of participants was $39.07(11.42)$ years. The majority were male $(n=129 ; 56.1 \%)$, with most having at least 12 years of formal education $(n=140 ; 60.9 \%)$. Over half of the participants were single $(n=132 ; 57.4 \%)$ and unemployed $(n=140 ; 60.9 \%)$. 


\section{Clinical characteristics}

Less than half of the participants were currently psychotic when interviewed with the MINI $(n=101$; $43.9 \%)$ and most had not received inpatient care $(n=140 ; 60.9 \%)$. The majority was being managed with first-generation antipsychotics $(n=144 ; 62.6 \%)$, and just over a quarter on second-generation antipsychotics $(n=60 ; 26.1 \%)$; a minority was on a combination of firstand second-generation antipsychotics $(n=26 ; 11.3 \%)$. The routes of medication taking were oral alone $(n=125$;
$54.3 \%)$, oral and depot, or long-acting injections ( $n=101$; $43.9 \%)$, and depot alone $(n=4 ; 1.7 \%)$ (Table 1$)$.

\section{MARS scores}

The mean (standard deviation) MARS score was 3.92 (2.69). The scores ranged between 0 and 10 ; the median score was 4 , while the interquartile range was between 2 and 6 . There were no differences in mean MARS scores across gender $(t=0.25, \mathrm{p}=0.80)$ or whether inpatient care was received after a relapse

Table 1 - Sociodemographic and clinical characteristics of participants

\begin{tabular}{|c|c|c|}
\hline Variable & Frequency & Percentage \\
\hline \multicolumn{3}{|l|}{ Age range } \\
\hline $18-29$ & 53 & 23.0 \\
\hline $30-39$ & 79 & 34.3 \\
\hline $40-49$ & 52 & 22.6 \\
\hline $50-64$ & 46 & 20.0 \\
\hline Mean (standard deviation) & $39.07(11.42)$ & \\
\hline \multicolumn{3}{|l|}{ Gender } \\
\hline Male & 129 & 56.1 \\
\hline Female & 101 & 43.9 \\
\hline \multicolumn{3}{|l|}{ Employment status } \\
\hline Unemployed & 140 & 60.9 \\
\hline Employed & 90 & 39.1 \\
\hline \multicolumn{3}{|l|}{ Marital status } \\
\hline Single & 132 & 57.4 \\
\hline Married & 63 & 27.4 \\
\hline Separated/divorced/widow(er) & 35 & 15.2 \\
\hline \multicolumn{3}{|l|}{ Duration of formal education } \\
\hline$\leq 12$ years & 90 & 39.1 \\
\hline$>12$ years & 140 & 60.9 \\
\hline \multicolumn{3}{|l|}{ Previous inpatient care } \\
\hline No & 140 & 60.9 \\
\hline Yes & 90 & 39.1 \\
\hline \multicolumn{3}{|l|}{ Current psychosis on MINI } \\
\hline No & 129 & 56.1 \\
\hline Yes & 101 & 43.9 \\
\hline \multicolumn{3}{|l|}{ Class of medication(s) } \\
\hline First-generation antipsychotics alone & 144 & 62.6 \\
\hline Second-generation antipsychotics alone & 60 & 26.1 \\
\hline First- and second-generation antipsychotics & 26 & 11.3 \\
\hline \multicolumn{3}{|l|}{ Route of medication administration } \\
\hline Oral only & 125 & 54.3 \\
\hline Depot only & 4 & 1.7 \\
\hline Oral and depot & 101 & 43.9 \\
\hline
\end{tabular}


$(t=0.50, p=0.62)$. Participants with a MINI diagnosis of current psychosis were significantly more likely to show poorer adherence (4.96 vs. $3.11 ; t=5.50, \mathrm{p}<0.001$ ). Similarly, those receiving depot antipsychotics alone or in combination were significantly more likely to report poorer adherence (4.62 vs. 3.34; $t=3.70, p<0.001$ ). Responses to the MARS items are shown in Table 2.

\section{Reliability and factor structure}

The reliability of the MARS was tested and a score of 0.76 indicated good internal structure of the items. After one item was removed from the analysis, the scores ranged between 0.72 and 0.77 , suggesting minimal or no redundancy of items in the scale. Despite the moderate to good alpha score obtained, the factor structure of the MARS was assessed using a principal component and factor analysis with varimax rotation, with Eigenvalues greater than 1 being retained. A 3-factor solution was produced (Table 3). Factors 1 to 3 accounted for 28.7, 15.1 and $14.6 \%$ of the variance, respectively, at a total of $58.4 \%$. The reliability of the three factors were: factor $1,0.80$; factor $2,0.50$; and factor $3,0.54$.

Table 2 - Participants' responses to the items of the Medication Adherence Rating Scale

\begin{tabular}{lcc}
\hline Variable & \multicolumn{1}{c}{ Frequency, n (\%) } & No \\
\hline Do you ever forget to take your medication? & $108(47.0)$ & $122(53.0)$ \\
Are you careless at times at taking medication? & $90(39.1)$ & $140(60.9)$ \\
When you feel better do you sometimes stop taking your medication? & $115(50.0)$ & $115(50.0)$ \\
Sometimes if you feel worse when you take the medication do you stop taking it? & $108(46.9)$ & $122(53.1)$ \\
I take my medication only when I am sick & $86(37.4)$ & $115(50.0)$ \\
It is unnatural for my mind and body to be controlled by medication & $51(22.1)$ & $115(50.0)$ \\
My thoughts are clearer on medication & $80(34.8)$ & $179(77.9)$ \\
By staying on medication, I can prevent getting sick & $29(12.6)$ & $150(65.2)$ \\
I feel weird, like a zombie, on medication & $102(44.3)$ & $201(87.4)$ \\
Medication makes me feel tired and sluggish & $128(55.7)$ \\
\hline
\end{tabular}

Table 3 - Confirmatory factor analysis of the MARS

\begin{tabular}{|c|c|c|c|}
\hline \multirow[b]{2}{*}{ Variable } & \multicolumn{3}{|c|}{ Component } \\
\hline & Factor 1 & Factor 2 & Factor 3 \\
\hline Do you ever forget to take your medication? & 0.552 & $(0.373)$ & $(0.205)$ \\
\hline Are you careless at times at taking medication? & 0.655 & $(0.316)$ & $(0.180)$ \\
\hline When you feel better do you sometimes stop taking your medication? & 0.720 & $(0.130)$ & $(0.167)$ \\
\hline $\begin{array}{l}\text { Sometimes if you feel worse when you take the medication do you stop } \\
\text { taking it? }\end{array}$ & 0.719 & $(0.042)$ & $(-0.021)$ \\
\hline I take my medication only when I am sick & 0.746 & $(0.175)$ & $(-0.012)$ \\
\hline It is unnatural for my mind and body to be controlled by medication & 0.710 & $(-0.031)$ & $(-0.097)$ \\
\hline My thoughts are clearer on medication & $(0.088)$ & 0.821 & $(0.066)$ \\
\hline By staying on medication, I can prevent getting sick & $(0.168)$ & 0.741 & $(-0.065)$ \\
\hline I feel weird, like a zombie, on medication & $(-0.008)$ & $(0.035)$ & 0.813 \\
\hline Medication makes me feel tired and sluggish & $(0.101)$ & $(-0.008)$ & 0.824 \\
\hline
\end{tabular}




\section{Relationship with psychopathology}

Total MARS scores had a weak but statistically significant association with the PANSS positive subscale $(r=-0.22, p<0.001)$, with greater severity of positive symptoms associated with better adherence. A similar relationship was observed with the general subscale of the PANSS $(r=-0.18, p<0.01)$. There was no significant relationship with the negative subscale of the PANSS $(r=-0.02, p=0.82)$.

\section{Relationship with insight}

Total MARS scores showed a weak but statistically significant relationship with awareness of mental illness and response to medications $(r=-0.21, p<0.001)$, as well as with awareness of positive symptoms $(r=-0.15$, $p<0.02$ ). No relationship was observed between total MARS scores and awareness of negative symptoms $(r=-0.09, p=0.20)$. Medication adherence behavior (factor 1 ) was significantly associated with awareness of mental illness $(r=0.39, p<0.001)$, awareness of positive symptoms $(r=0.30, p<0.001)$, and awareness of negative symptoms $(r=0.18, p<0.01)$. Attitude to taking medications (factor 2 ) was significantly associated with awareness of mental illness ( $r=0.53$, $p<0.001)$, awareness of positive symptoms ( $r=0.50$, $p<0.001)$, and awareness of negative symptoms $(r=0.26, p<0.001)$. Negative side effects and attitude to psychotropics (factor 3) showed no significant associations with awareness of mental illness $(p=0.39)$, awareness of positive symptoms $(p=0.28)$, or awareness of negative symptoms $(p=0.83)$

\section{Discussion}

This study confirms that the MARS is a multidimensional construct assessing medication adherence in persons with schizophrenia. The MARS was reduced to three factors, consistent with earlier studies, but did not demonstrate strong external validity as its associations with current psychotic status, severity of psychopathology, insight as well as route of medication administration and dosage (measured in chlorpromazine equivalents) were weak though statistically significant.

Reliability indices of the overall scale have varied across studies. While the developer of the scale ${ }^{22}$ reported a value of 0.75 , similar to our value of 0.76 , other researchers have reported lower values, between $0.6^{12,13}$ and $0.56,{ }^{23}$ respectively. Differences in reliability indices across studies may be due to the small number of items and the binary response format of the MARS compared to Likert-type responses, which produce higher reliability indices. The reliability results of the three factors were $0.80,0.50$, and 0.54 for factors 1,2 , and 3, respectively. The first factor (medication adherence behavior) showed a very good reliability index. Previous reports are consistent in identifying this factor as the most reliable one. ${ }^{12,23,24}$

Even though this study confirmed a 3-factor structure for the MARS, consistent with some previous reports, other authors have suggested 2- and 5-factor structures based on their analysis. In contrast to the findings of Thompson et al. ${ }^{7}$ and Fialko et al., ${ }^{25}$ in our study, the first factor from the confirmatory factor analysis comprised 6 items vs. 5 items from previous research. This may have accounted for the improved reliability of this factor in this study, as well as the consistency of this factor in external validity testing. The additional item, "It is unnatural for my mind and body to be controlled by medication," on face validity, appears to be more consistent with medication adherence behavior than attitude to taking medication, as classed in previous reports. This factor from this study clearly describes negative behaviors or cognition that impede medication adherence or promote poor or non-adherence. Furthermore, the remaining two factors have reliability metrics that are consistent with those reported previously, although they both contain only two items each.

Ideally, validity testing of the MARS should be against a gold standard or objective measure. Drug assays, for example, may demonstrate the true sensitivity and specificity of the MARS. While comparison with other self-report measures and interviewer- or clinicianrated adherence have shown some consistency, selfreport measures tend to overestimate adherence when compared to other objective assessments. ${ }^{8}$ The MARS showed weak external validity when assessed in relation to severity of illness, insight and route of medication administration. The weak scores are consistent with studies from Europe ${ }^{13,25}$ and suggest that there are likely other factors that mediate the relationship between adherence on the one hand and insight or illness severity on the other, and that have not been identified or captured in adherence measures. In Nigeria, as in other developing countries, the family or caregiver strongly influences medication adherence. They may be ensuring medication compliance by administering medications themselves, or withhold rewards when patients are nonadherent to medications. Patients may also be using medications for other reasons; it may go beyond the fact that they believe they are ill, but use medications for example to improve sleep. The absence of unidentified factors that influence medication adherence is explained by the fact that the 3-factor structure explained less than $60 \%$ of the variability of the scores. Clinicians use 
depot preparations (long-acting injections) in the care for persons with schizophrenia to overcome poor or non-adherence to medications. We observed that the MARS discriminated well these cases, with significantly lower scores obtained for those already identified by their clinicians as being probably poorly adherent and currently receiving oral/depot combinations or depot preparations alone.

The attitude to taking medication domain comprised items 7 and 8 of the MARS in this cohort. Both questions appear to explore insight towards the illness. We observed that there was a significant but moderate correlation between item 7 on the MARS and the awareness of the need for treatment domain in the SUMD (analysis not shown). The domain on negative side effects of medication showed a high factor loading. The high loading may result from a preponderance of participants on first-generation antipsychotics, which, though effective, can have notable side effects of bradykinesia and rigidity.

Our findings should be taken into consideration with some limitations in view. First, it would have been ideal to compare subjective rating of adherence with health worker-rated perception of adherence; however, we utilized an "indirect" measure of adherence which was to identify participants on depot preparations, who receive such preparations primarily due to poor or non-adherence. ${ }^{26}$ Second, while this study overcomes a limitation identified by Fialko et al. ${ }^{25}$ in using an outpatient population exclusively, it may not be entirely representative of persons with schizophrenia who do not attend outpatient care. Thirdly, a cross-sectional design does not allow for the assessment of adherence over time, or of the stability of the MARS over time as a result.

\section{Conclusion}

This study confirms the dimensional structure of the MARS, in line with other studies. It discriminated well between participants on depot preparations compared to those on oral medications. Even though internal consistency was strong, external validity testing showed weak to moderate associations with illness severity and insight. Further research is needed with larger sample sizes and a cohort study design.

\section{Disclosure}

No conflicts of interest declared concerning the publication of this article.

\section{References}

1. Czobor P, Van Dorn RA, Citrome L, Kahn RS, Fleischhacker WW, Volavka J. Treatment adherence in schizophrenia: A patientlevel meta-analysis of combined CATIE and EUFEST studies. Eur Neuropsychopharmacol. 2015;25:1158-66.

2. Adewuya $A O$, Owoeye $O A$, Erinfolami AR, Coker AO, Ogun OC, Okewole AO, et al. Prevalence and correlates of poor medication adherence amongst psychiatric outpatients in southwestern Nigeria. Gen Hosp Psychiatry. 2009;31:167-74.

3. Borras L, Mohr S, Brandt P-Y, Gilliéron C, Eytan A, Huguelet P. Religious beliefs in schizophrenia: their relevance for adherence to treatment. Schizophr Bull. 2007;33:1238-46.

4. Okpataku CI, Kwanashie HO, Ejiofor JI, Olisah VO. Medication compliance behavior in psychiatric out - patients with psychoactive substance use comorbidity in a Nigerian tertiary hospital. Niger J Clin Pract. 2015;18:371-6.

5. Mak KY, Lo WTL, Yeung WS, Wong M, Chung WSD, Chui E, et al. Consensus statements on adherence issues in schizophrenia for Hong Kong. Asian J Psychiatr. 2014;12:163-9.

6. SendtK-V, Tracy DK, Bhattacharyya S. A systematic review of factors influencing adherence to antipsychotic medication in schizophreniaspectrum disorders. Psychiatry Res. 2015;225:14-30.

7. Thompson K, Kulkarni J, Sergejew AA. Reliability and validity of a new Medication Adherence Rating Scale (MARS) for the psychoses. Schizophr Res. 2000;42:241-7.

8. Alcaide $M L$, Ramlagan $S$, Rodriguez VJ, Cook $R$, Peltzer $K$, Weiss SM, et al. Self-report and dry blood spot measurement of antiretroviral medications as markers of adherence in pregnant women in rural South Africa. AIDS Behav. 2017;1-6.

9. Nguyen TMU, Caze AL, Cottrell N. What are validated self-report adherence scales really measuring?: a systematic review. $\mathrm{Br}$ J Clin Pharmacol. 2014;77:427-45.

10. Arute JE, Eniojukan JF, Eboigbe N. Adherence to psychotropic medications by outpatients in psychiatric hospital, Uselu Benin City, Nigeria. Value Heal. 2014;17:A460-1.

11. Hogan TP, Awad AG, Eastwood R. A self-report scale predictive of drug compliance in schizophrenics: reliability and discriminative validity. Psychol Med. 1983;13:177.

12. Fialko L, Garety PA, Kuipers E, Dunn G, Bebbington PE, Fowler D, et al. A large-scale validation study of the Medication Adherence Rating Scale (MARS). Schizophr Res. 2008;100:53-9.

13. Zemmour K, Tinland A, Boucekine M, Girard V, Loubière S, Resseguier $\mathrm{N}$, et al. Validation of the Medication Adherence Rating Scale in homeless patients with schizophrenia: results from the French housing first experience. Sci Rep. 2016;6:31598.

14. Sheehan D V, Lecrubier Y, Sheehan KH, Amorim P, Janavs J, Weiller $\mathrm{E}$, et al. The Mini-International Neuropsychiatric Interview (M.I.N.I.): the development and validation of a structured diagnostic psychiatric interview for DSM-IV and ICD-10. J Clin Psychiatry. 1998;59:22-33-57.

15. Adewuya AO. Validation of the Alcohol Use Disorders Identification Test (AUDIT) as a screening tool for alcohol-related problems among Nigerian university students. Alcohol. 2005;40:575-7.

16. Adewuya AO, Makanjuola ROA. Subjective quality of life of Nigerian schizophrenia patients: sociodemographic and clinical correlates. Acta Psychiatr Scand. 2009;120:160-4.

17. Iteke $\mathrm{O}$, Bakare $\mathrm{MO}$, Agomoh $A O$, Uwakwe $\mathrm{R}$, Onwukwe JU. Road traffic accidents and posttraumatic stress disorder in an orthopedic setting in south-eastern Nigeria: a controlled study. Scand J Trauma Resusc Emerg Med. 2011;19:39.

18. Kay SR, Fiszbein A, Opler LA. The positive and negative syndrome scale (PANSS) for schizophrenia. Schizophr Bull. 1987;13:26176.

19. Adewuya AO, Ola BA, Mosaku SK, Fatoye FO, Eegunranti AB. Attitude towards antipsychotics among out-patients with schizophrenia in Nigeria. Acta Psychiatr Scand. 2006;113:207-11.

20. Igberase OO, Morakinyo O, Lawani AO, James BO, Omoaregba JO. Burden of care among relatives of patients with schizophrenia in midwestern Nigeria. Int J Soc Psychiatry. 2012;58:131-7.

21. Moreira IC, Bandeira M, Pollo TC, Oliveira MS de. Cross-cultural adaptation to Brazil of Medication Adherence Rating Scale for psychiatric patients. J Bras Psiquiatr. 2014 Dec;63(4):273-80.

22. Thompson K, Kulkarni J, Sergejew A. Reliability and validity of a new Medication Adherence Rating Scale (MARS) for the psychoses. Schizophr Res. 2000;42:241-7.

23. Jaeger $S$, Pfiffner $C$, Weiser $P$, Kilian R, Becker $T$, Längle $G$, et al. Adherence styles of schizophrenia patients identified by a latent 
class analysis of the Medication Adherence Rating Scale (MARS): A six-month follow-up study. Psychiatry Res. 2012;200:83-8.

24. Vanelli I, Chendo I, Gois C, Santos J, Levy P. Medication adherence rating scale. Acta Med Port. 24:17-20.

25. Fialko L, Garety P, Kuipers E, Dunn G, Bebbington P, Fowler D, et al. A large-scale validation study of the Medication Adherence Rating Scale (MARS). Schizophr Res. 2008;100:53-9.

26. James BO, Omoaregba JO, Okonoda KM, Otefe EU, Patel MX. The knowledge and attitudes of psychiatrists towards antipsychotic long-acting injections in Nigeria. Ther Adv Psychopharmacol. 2012;2:169-77.

\section{Correspondence:}

Bawo O. James

Department of Clinical Services, Federal Neuro-Psychiatric Hospital

PMB 1108

300212 - Benin City, Nigeria

Tel.: +234-8023715213

E-mail: bawojames@yahoo.com 